\title{
Rieger Syndrome Type 1
}

National Cancer Institute

\section{Source}

National Cancer Institute. Rieger Syndrome Type 1. NCI Thesaurus. Code C75015.

A rare autosomal dominant syndrome linked to mutations in the PITX2 gene. It is characterized by abnormalities in the anterior chamber of the eye and underdevelopment of the teeth. 